pp 1013-1033. (C) The Author(s), 2021. Published by Cambridge University Press on behalf of Royal Aeronautical Society. This is an Open Access article, distributed under the terms of the Creative Commons Attribution licence (http://creativecommons.org/licenses/by/4.0/), which permits unrestricted reuse, distribution, and reproduction in any medium, provided the original work is properly cited.

doi:10.1017/aer.2021.6

\title{
Impact of aromatic species selection and micro and bulk properties of alternative fuels on atomisation
}

\author{
C.J. Wijesinghe \\ Mechanical Engineering Department \\ The University of Sheffield \\ Sheffield \\ UK
}

\author{
B. Khandelwal(i) \\ bhupendra.khandelwal@gmail.com \\ Mechanical Engineering Department \\ The University of Alabama \\ Tuscaloosa, Alabama \\ USA
}

\section{ABSTRACT}

The importance of fuel injection methods and their atomisation characteristics has been well described in literature. Also, there are a large number of studies in literature detailing the impact of bulk properties of conventional fuels on atomisation and spray characteristics. However, there is a lack of knowledge on how different alternative fuels, and specifically aromatic species, impact spray and atomisation characteristics. In this investigation, the impact of alternative fuels, selected aromatic species and their properties on spray atomisation was studied. Details of how different aromatic structures, bonds and other micro properties of aromatics species impact spray and atomisation characteristics were investigated. To achieve this objective, testing was conducted using a Rolls-Royce Tay engine fuel injector. It was found that the droplet sizes in the form of the Sauter Mean Diameter (SMD) correlate well with fuel properties including density, viscosity and surface tension, which is in line with other published literature. Moreover, it was found that there are several aromatic species (ethylbenzene, cumene and tert-butylbenzene) which display improved atomisation. This indicates that the size of the aliphatic groups attached to the benzene ring in the aromatic molecule impact on the drop size and thereby the combustion characteristics. The worst performers were polyaromatic naphthalene compounds. With the increasing push for fuels with selected aromatic species in the future, this study provides knowledge on the impact of their on the atomisation characteristics. 
Keywords: Atomisation; Alternative fuels; Sprays; Fuel properties; Aromatic; Hydrocarbons

\section{NOMENCLATURE}

$\begin{array}{ll}\text { ALR } & \text { air-to-liquid ratio } \\ \text { ATJ } & \text { alcohol-to-jet } \\ \text { DCN } & \text { derived cetane number } \\ \text { FT } & \text { Fischer-Tropsch process and/or fuels derived from it } \\ \text { GTL } & \text { gas-to-liquid } \\ \text { HEFA } & \text { hydro-processed esters and fatty acids } \\ \text { H/C } & \text { hydrogen-to-carbon ratio } \\ \text { IPK } & \text { iso-paraffinic kerosene } \\ \text { LBO } & \text { lean blowout } \\ \text { PTFE } & \text { polytetrafluoroethylene } \\ \text { Q } & \text { volume flow rate } \\ \text { SMD } & \text { Sauter mean diameter, also denoted by } D_{32} \\ \text { SPK } & \text { synthetic paraffinic kerosene } \\ \sigma & \text { surface tension } \\ \mu & \text { viscosity } \\ \text { U } & \text { velocity }\end{array}$

\subsection{INTRODUCTION}

Spray or fuel atomisation characteristics are considered to be paramount in determining the performance characteristics of gas turbines ${ }^{(1,2)}$. In essence, this is due to the role of the injector in mixing the air and fuel in a given combustion chamber; the more thoroughly mixed the fuel and air are, the better the combustion will be in terms of instability efficiency and even emissions. Therefore, it stands to reason that, if a fuel can adversely affect the atomisation of a given fuel injector, the vast majority of which have been optimised for use with Jet A and Jet A-1, this would affect the combustion instability characteristics of the engine ${ }^{(3,4)}$. With the increasing use of alternative fuels, several studies that discuss the spray characteristics of alternative fuels have been published recently times ${ }^{(5-9)}$.

'Atomisation' is a term used to describe in essence the transformation of liquid fuel into small droplets or a spray before being burned in a gas turbine combustor or any other liquid fuel burner. Contrary to what the name suggests, these liquids are not literally broken into individual atoms but more of a fine mist. A more elegant definition has been provided by Mansour and Chigier "atomisation is a process in which the surface to mass ratio of a liquid is increased"(10). For a given liquid, two properties stand out in affecting the droplet size, shape and ease of formation: the surface tension and the viscosity.

Airblast atomisers are widely used in the aviation industry. The seminal equation for the SMD of twin-fluid atomisers was defined by Nukiyama and Tanasawa and subsequently improved by Lefebvre ${ }^{(11,12)}$. The base equation for the SMD by Nukiyama and Tanasawa is ${ }^{(1)}$

$$
D_{32}=0.585\left(\sigma / \rho_{L} U_{R}^{2}\right)^{0.5}+53\left(U_{L}^{2}\right)^{0.225}\left(Q_{L} / Q_{A}\right)^{1.5}
$$


where $\mu$ is the viscosity of the liquid fuel and $Q$ is the volume flow rate. The subscripts $L$ and $A$ denote liquid and air, respectively. The air terms in this equation refer to the atomisation air rather than atmospheric air. A noticeable omission from this equation is the absence of a characteristic dimension for the nozzle geometry. The reasoning for this is that, in experimental studies, it has been shown that nozzle geometry does not impact the droplet diameter ${ }^{(11)}$. Furthermore, it should be noted that, in this equation, there are terms for the density surface tension and viscosity of the fuel, which indicate that these properties do have an impact on the drop size produced by the injector. Therefore, these properties are considered in this investigation to compare alternative fuels and their injection characteristics.

The importance of aromatic components in jet fuel pertain to their ability to aid in overall lubricity and seal swell ${ }^{(13-16)}$. This is imperative to maintain the integrity of the aircraft's fuel system. However, this must be balanced against the fact that aromatic compounds tend to generate increased particulate emissions ${ }^{(14,17-19)}$, which in turn motivates study into the injection characteristics of such compounds.

The importance of fuel injection methods and their fuel atomisation characteristics has been well described in literature ${ }^{(1,5,6,20-26)}$. Also, there are large number of studies in literature detailing the impact of the bulk properties of conventional fuels on atomisation and spray characteristics $^{(5,7,8,12)}$. However, there is a lack of knowledge on how different alternative fuels, especially with selected aromatics species, and their properties impact the atomisation and spray characteristics. Hence, in this investigation, it was considered prudent to study fuels with selected aromatic species and other alternative fuels as well as their impact on the fuel spray characteristics when injected through a gas turbine fuel injector. Another aim of this study is to investigate how different aromatic structures, bonds and other micro properties of aromatics species impact the spray and atomisation characteristics. With the increasing push for selected aromatic species fuels in the future, this study provides knowledge on the impact of selected aromatic species on atomisation characteristics. One of the major contributions of this study is to provide knowledge on how these alternative and aromatic species fuels perform in the fuel injection phase of combustion. Table 1 lists the drop-in alternative and reference fuels tested in this study.

\subsection{Fuels and blends tested in this study}

Table 2 depicts the aromatic compounds used in this investigation, for the most part consisting of polycyclic and monocyclic aromatic compounds with indene, indan, tetralin and methylnaphthalene as complex aromatics. The quoted density was obtained from the manufacturer and is accurate at $15^{\circ} \mathrm{C}$. The Hydrogen-to-Carbon $(\mathrm{H} / \mathrm{C})$ ratio has also been calculated. Due to cost and the impracticalities of testing these compounds neat, it was decided to blend these aromatics with a baseline straight-chain solvent which only contained 99\% C9, C10, C11, $\mathrm{C} 12$, and $\mathrm{C} 14$ by volume. The solvent was commercial in nature and manufactured by Banner Chemicals UK with the name Banner NP1014. The aromatics were blended in two ratios, namely $8 \%$ and $18 \%$, with the balance in volume being solvent. The blending was achieved by volume in 10L batches of each aromatic blend. As the density of the aromatics and solvents were provided by the manufacturers (tested using ASTM D4052), the blending was completed by mixing the masses of solvent and aromatic required to achieve the required blend ratios of $18 \%$ and $8 \%$. The reason for blending masses to achieve a volume blend instead of using measuring cylinders is the large batch size of $10 \mathrm{~L}$, for which scales accurate to $\pm 0.1 \mathrm{~g}$ were used. 
Table 1

Reference fuel properties

\begin{tabular}{|c|c|c|c|c|c|c|}
\hline $\begin{array}{l}\text { Fuel } \\
\text { code }\end{array}$ & Descriptor & $\begin{array}{c}\text { Density at } \\
15^{\circ} \mathrm{C} \\
\left(\mathrm{kg} / \mathrm{m}^{3}\right)(\mathrm{ASTM} \mathrm{D4052})\end{array}$ & $\begin{array}{r}\text { Surface tension } \\
\text { at } 22^{\circ} \mathrm{C}(\mathrm{mN} / \mathrm{m}) \\
(\mathrm{ASTM} \mathrm{D1331})\end{array}$ & $\begin{array}{l}\text { Derived cetane number } \\
\text { (ASTM D613) }\end{array}$ & $\begin{array}{l}\text { Flash point } \\
\left({ }^{\circ} \mathrm{C}\right) \\
(\text { ASTM D93) }\end{array}$ & $\begin{array}{r}\text { Viscosity } \\
-20^{\circ} \mathrm{C} \\
\text { (cSt) (ASTM }\end{array}$ \\
\hline RF1 & Average Jet A & 803.2 & 24.8 & 48.3 & 48 & 4.5 \\
\hline RF2 & $\begin{array}{c}\text { Kerosene with lubricity and } \\
\text { anti-corrosion additives }\end{array}$ & 779.9 & 23.8 & 48.8 & 42 & 3.5 \\
\hline RF3 & $\begin{array}{l}\text { Worst-case high-flash-point } \\
\text { kerosene }\end{array}$ & 826.8 & 25.7 & 39.2 & 60 & 6.5 \\
\hline RF4 & $100 \%$ Gevo ATJ & 759.7 & 23.4 & 17.1 & 49.5 & - \\
\hline RF5 & $\begin{array}{l}\text { Highly viscous fuel blend } \\
\text { (64\% RF3 balance } \\
\text { farnesane) }\end{array}$ & 807.7 & 26.1 & 47 & 66 & - \\
\hline RF6 & $\begin{array}{l}\text { Low-cetane fuel blend } \\
\qquad(60 \% \text { Sasol IPK balance } \\
\text { ATJ })\end{array}$ & 759.2 & 22.7 & 28 & 46 & 3.9 \\
\hline RF7 & $\begin{array}{l}\text { Narrow boiling point blend } \\
\text { ( } 73 \% \mathrm{C} 10 \text { balance } \\
\text { trimethyl benzene) }\end{array}$ & 768.9 & 23.8 & 39.6 & 44 & 1.9 \\
\hline RF8 & $\begin{array}{l}\text { Blend of fuel high in } \\
\text { cycloparaffins }\end{array}$ & 818.1 & 26.1 & 42.85 & 64 & 6.5 \\
\hline RF9 & High-aromatic blend & 823.0 & 26.5 & 43.1 & 56 & 4.8 \\
\hline RF10 & $\begin{array}{l}\text { High-cetane-number blend } \\
\text { achieved using only } \\
\text { HEFA and SPKs }\end{array}$ & 759.0 & 24.5 & 63.3 & 48 & 5.5 \\
\hline RF11 & Cetane verified blend & 777.0 & - & 31 & 50 & 4.3 \\
\hline RF12 & Cetane verified blend & 786.0 & - & 44 & 38 & 4.6 \\
\hline RF13 & Cetane verified blend & 786.0 & - & 54 & 56 & 5 \\
\hline
\end{tabular}


Table 2

Aromatic blend details

\section{Fuel identifier Aromatic}

\section{1}

2

3

4

5

6

7

8

9

10

11

12

13

14

15

16
Toluene

Styrene

$o$-Xylene

Ethylbenzene

Indene

Indan

$\alpha$-Methylstyrene

Pseudocumene

Cumene

Tetralin

Diethylbenzene

Tert-butylbenzene

p-Cymene

Methylnaphthalene

3-Isopropylcumene

Tert-butyl-m-Xylene

\section{$\mathrm{H} / \mathrm{C}$ ratio of aromatic compound $\left(\mathrm{kg} / \mathrm{m}^{3}\right)$ (ASTM D4052)}

1.143

760.12

1

1.25

1.25

0.889

1.111

1.111

1.333

1.333

1.2

1.4

1.4

1.4

0.909

1.5

1.5
763.4

761.24

760.28

770.6

768.12

763.64

761

760.04

768.76

760.52

760.28

759.72

771

759.4

760.28

The $H / C$ ratio presented in Table 2 is for the aromatic compound only and has been calculated using the molecular formula of the compound. These particular ratios were arrived at after considering the average total aromatic content present in jet fuel (approximately $18 \%$ according to literature) and the minimum aromatic content present in mainstream jet fuel (i.e. Jet A, Jet A1 and JP8) of around 8\% ${ }^{(15,27-29)}$. However, note that both Def Stan 91-091 and ASTM D1655 allow for a maximum of $25 \%$ aromatic content by volume ${ }^{(30,31)}$. The two blend ratios were given a code for ease of reference in this study, with $8 \%$ being $A$ and $18 \%$ being $B$. So, for example the blend of Tetralin at $8 \%$ would be fuel $A 10$ while the $18 \%$ blend would be fuel $B 10$.

\subsection{EXPERIMENTAL SETUP}

A Rolls-Royce Tay combustor fuel injector was used in this study. The tests were conducted in an enclosed cubicle (Fig. 1). The cubicle itself was continuously purged with nitrogen from a cylinder bank to maintain a low-oxygen environment to reduce unwanted combustion from occurring inside. Purging with nitrogen also aids in cleaning the chamber air, to reduce the margin of error. The nitrogen ingress rate into the chamber is around $20 \mathrm{~L} / \mathrm{min}$ so as not to disturb the spray with undesirable air turbulence inside the cubicle. The chamber is continuously evacuated from a low level to remove the heavier fuel vapours as well as to mitigate the risk of spontaneous combustion. This process also allows the time between tests to be reduced as the previous test's vapours are dissipated rather quickly. Figure 1 depicts the entirety of the spray rig.

The chamber itself was mainly constructed from Perspex, with aluminium supports and the injection assembly suspended from the roof of the chamber. The particle sizer was mounted 


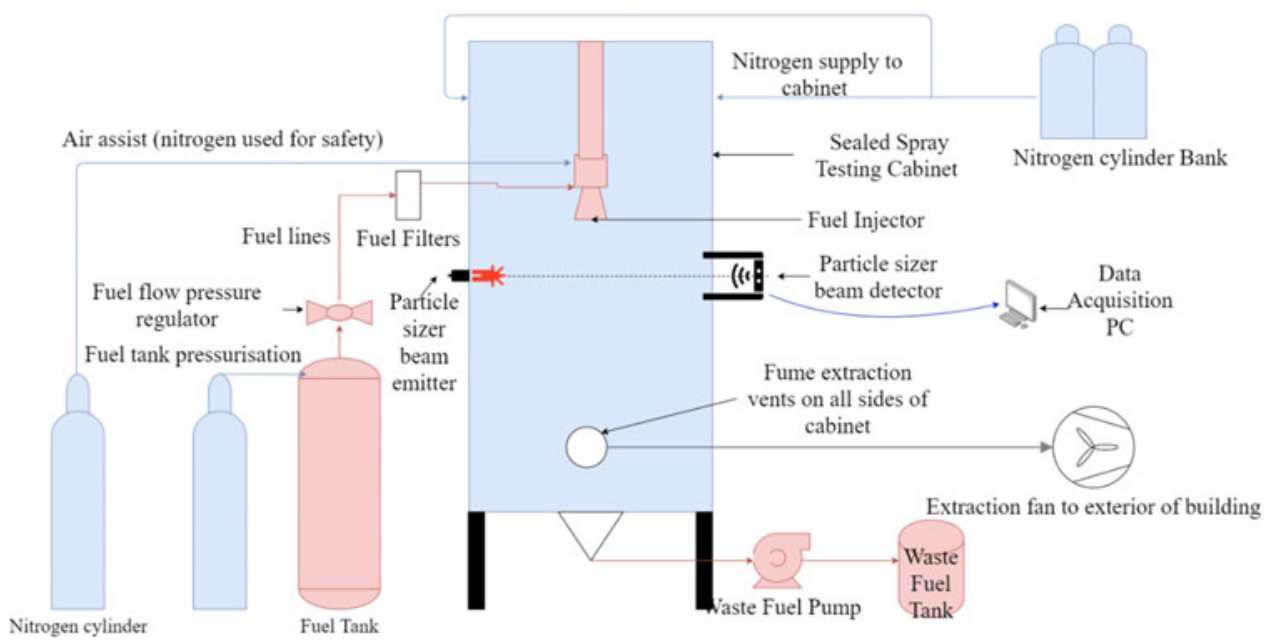

Figure 1. Spray testing rig.

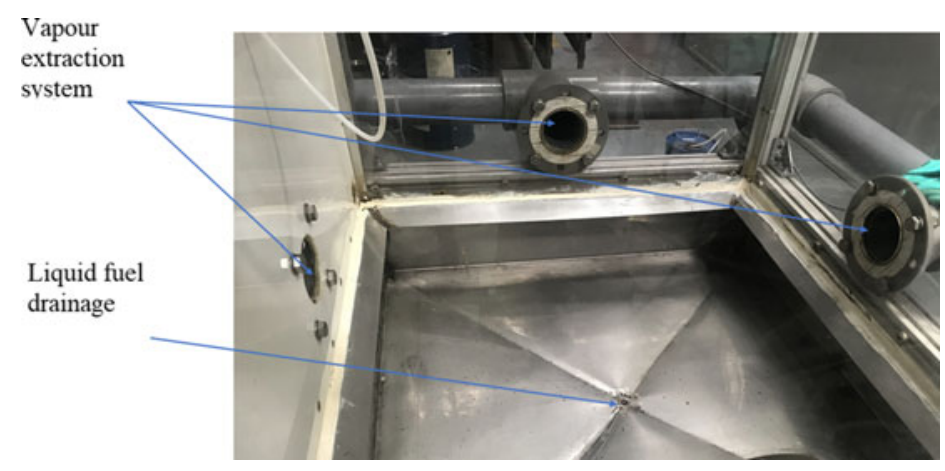

Figure 2. Spray rig bottom vents and liquid drainage.

in the same location as the injector assembly but $7 \mathrm{~cm}$ below the atomiser, which enables the sizer to capture a good cross section of the spray so as to be able to successfully compare the different fuels as well as literature results ${ }^{(5)}$. Approximately $0.5 \mathrm{~m}$ below the analyser level are the fume extraction vents, which vent the fuel vapours to the exterior of the building.

Figure 2 shows the interior portion of the spray cubicle where the vapour extraction system and the liquid drain are located. The liquid drain is connected to a waste fuel pump and then onto a small waste fuel drum, also slightly visible in the figure. The fuel system included a pressurised fuel tank (also pressurised using nitrogen for safety reasons) connected using PTFE tubes and Swagelok compression fittings to the injector assembly. The tank was filled with approximately $3 \mathrm{~L}$ of fuel per test. This was more than enough to complete the nine test points per fuel conducted in the investigation. At the end of each test, the fuel tank was drained using the valve located at the bottom of the tank. This was done while the tank was pressurised to expedite the draining process, and the injector was also opened so that any fuel remaining in the lines would either drop back into the tank or be injected into the chamber and evacuated that way. Once drained, the tank was flushed using isopropyl alcohol to effectively 'clean' the tank, fuel lines and injectors in preparation for the next fuel. Isopropyl alcohol was 


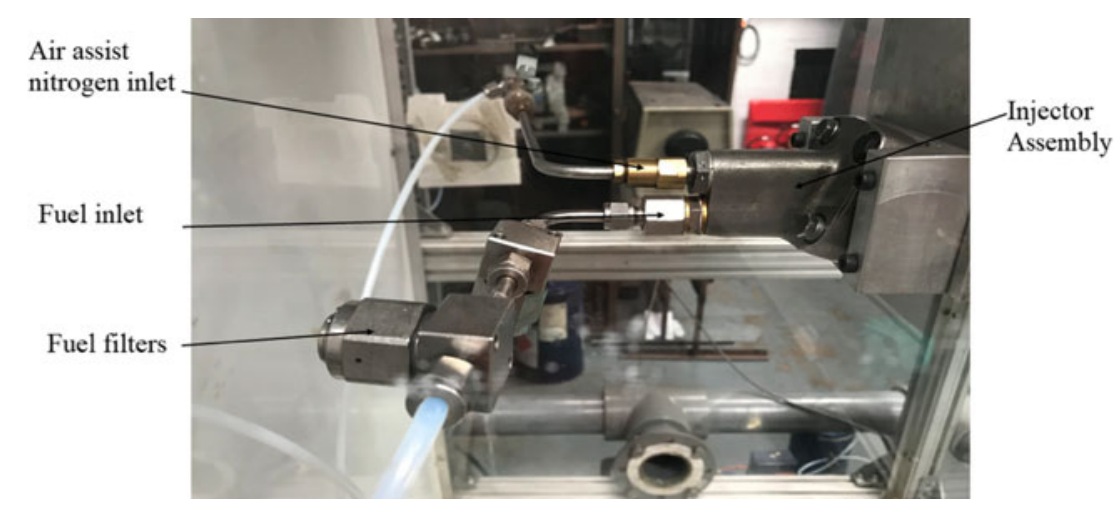

Figure 3. Injector assembly and fuel filters.

chosen for this procedure due to its quick-drying nature. The next fuel was then pumped into the tank and pressurised, and the injector was opened without taking a reading to ensure that droplets of the previous fuel in the line would be flushed out, leaving only the current fuel in the line and injector.

Figure 3 shows the injector assembly with the fuel and air assist inlets; the figure also portrays the fuel filters used in the testing. These were included in the testing to avoid clogging the injectors with any foreign objects or particles present in the fuel. The filters had a pore size of $60 \mu \mathrm{m}$.

A twin-fluid atomiser from a Rolls-Royce Tay engine was used in this study. The advantages of using a twin-fluid atomiser as opposed to a pressure atomiser (which, as the name suggests, uses the pressure of the fuel to force it through a small discharge orifice to achieve atomisation) lies in the fact that, for a given combustor design, the fuel discharge orifice is sized to the maximum fuel flow rate. This means that anything below the maximum fuel flow rate would result in poor atomisation from a pressure atomiser due to the lower differential fuel pressure. Twin-fluid atomisers mitigate this issue by supplementing the fuel atomisation with high-speed air which will aid atomisation across a wide range of fuel flow conditions ${ }^{(12)}$. Twin-fluid atomisers themselves are dichotomous, in that some are classified as 'air-assist' but others as 'air-blast' atomisers ${ }^{(12)}$. Whilst both are largely similar technologies, the differentiating feature is the amount of air assist involved and its velocity. Air-blast atomisation was used in this investigation as it is most representative of in-service aircraft engines due to their lower fuel pump pressure requirements. In this investigation, the atomisation air pressure was regulated and maintained constant at 14.5038psi. Figure 4 shows the details of the spray injector used in this study. All pressures for both air assist and injection in this study are denoted as gauge pressure.

The particle sizer used in this study was a Malvern 2600c particle sizer. This particular device is classified as a non-imaging optical analyser as it operates without needing to form an image of the scanned particles on the detector module. The particle sizer operates using conventional Fourier optical principles with a helium-neon $(\mathrm{He}-\mathrm{Ne})$ laser beam with a diameter of $18 \mathrm{~mm}$. The laser beam is monochromatic (red in colour, as this is dependent on the wavelength of the laser) and collimated, i.e. composed of only parallel rays of photons. The beam is then projected onto the receiving unit; the gap between the emitter and the receiver minus a minimum detection distance forms the usable detection area of the device. The perfectly parallel (collimated) beam is interrupted by particles (i.e. the substance used as a sample in the 

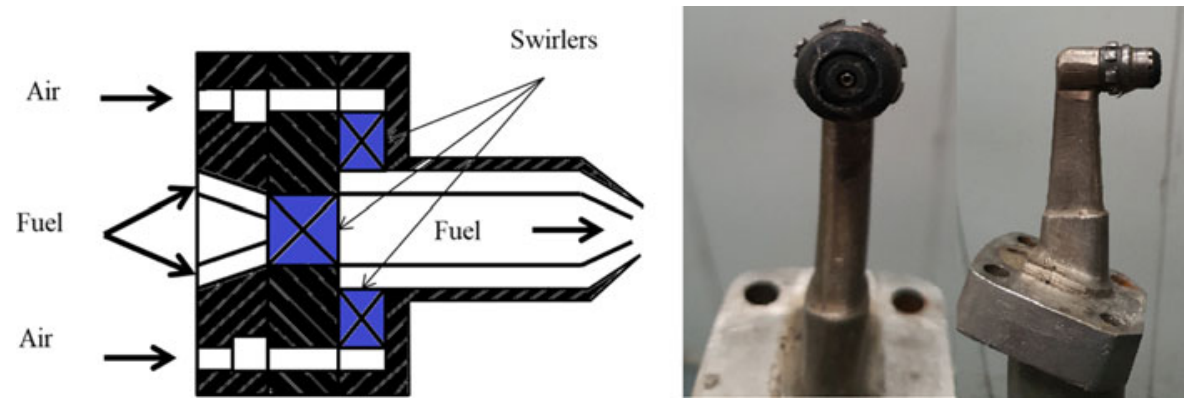

Figure 4. Air-blast atomiser and schematic from the Rolls-Royce Tay engine.

sizer) and is scattered; this scattering is measured by the detector and analysed to determine the size of the particles. The Malvern 2600 particle sizer is well suited for this application as it enables the measurement of continuous spray flows and has been used to characterise spray atomisers in literature ${ }^{(32,33)}$. The alignment of the sizer was checked before each test point.

Furthermore, it was necessary to account for the background light and other scattered particles inside the cubicle to obtain an accurate reading. The particle sizer accounts for this by using the 'set-zero' function, where a background reading is taken and later subtracted from the sample reading to ameliorate the effects of background light conditions or even residual particles from a previous spray. This process was carried out for each fuel tested. Furthermore, during preparatory tests, it was noted that, after each spray, there was a tendency for the cubicle to become misted with fuel vapour, which made the cubicle almost opaque. This phenomenon tended to skew the particle sizer data as the laser beam was strongly scattered by the mist. To rectify this issue, the extraction system was modified so that it would also extract from the top of the cubicle as well as the bottom corners. Whilst ameliorating the issue to a great extent, the procedure was amended to increase the time between tests so that the fuel mist would dissipate further with the aid of increased extraction.

\subsection{RESULTS AND DISCUSSION}

The fuels used in this investigation are the 16 aromatics presented in Table 2 blended with banner NP1014 in two ratios: 8\% (known as the A group, fuels A1-A16) and 18\% (known as the $\mathrm{B}$ group, fuels B1-B16). Also tested in this investigation are other alternative fuels described in Table 1. These fuels were tested using the apparatus described above in the experimental setup section. The fuels were tested at three specific fuel injection pressures 50, 60 and 70psi. The air assist pressure was kept constant at $14.5038 \mathrm{psi}$. The experiment was conducted under room temperature conditions of $20^{\circ} \mathrm{C}$. Three repeats were conducted for each test point, and the average taken for the variables collected. Error bars indicate one standard deviation of the range of droplet diameters measured in this investigation.

The first set of data stems from the particle size distributions themselves. The figures below show the particle size distributions for reference Jet A at injections pressure of 50psi (Fig. 5), 60psi (Fig. 6), and 70psi (Fig. 7). The horizontal axis portrays the droplet size in bins (due to space considerations and clarity, only one bound of the bin is depicted). For instance, the peak at $61 \mu \mathrm{m}$ in Fig. 5 corresponds to the percentage volume of particles that fall in-between 61.5 and $71.5 \mu \mathrm{m}$. The minimum particle size detected by the Malvern device was $1.5 \mu \mathrm{m}$. The left vertical axis depicts the percentage total volume of particles detected per bin (i.e. for Fig. 6, 


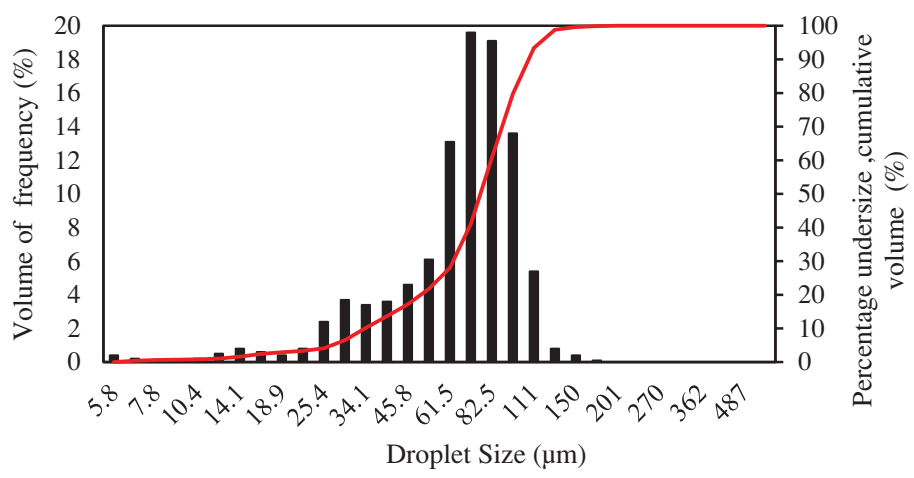

Figure 5. Jet A frequency undersize plot for 50psi injection pressure.
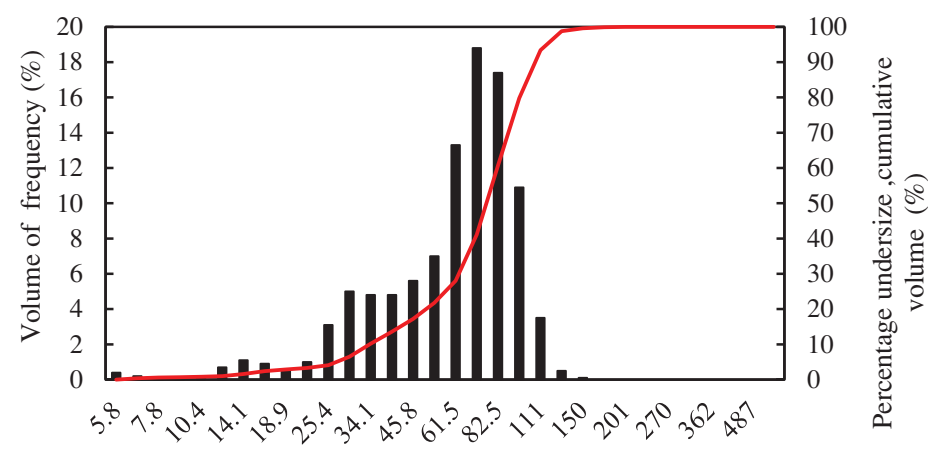

Droplet Size $(\mu \mathrm{m})$

Figure 6. Jet A frequency undersize plot for 60psi injection pressure.

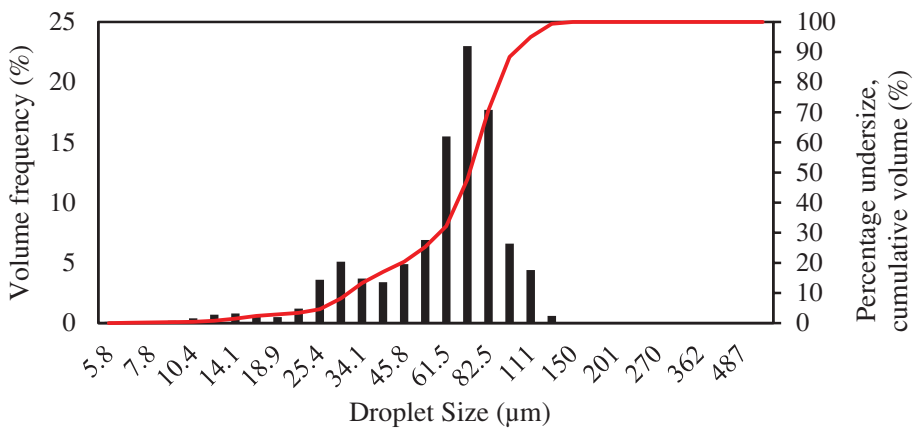

Figure 7. Jet A frequency undersize plot for $70 p s i$ injection pressure.

around $19 \%$ of all particles detected fell into the $71.5-82.5 \mu \mathrm{m}$ category). The right vertical axis corresponds to the cumulative frequency (the crimson line), which for Fig. 7 shows that around $90 \%$ of particles fall below $111 \mu \mathrm{m}$.

An interesting feature of these three figures is the slight bi-modality. It is clearly visible that the main volume of counts lies in the $71.5-82.5 \mu \mathrm{m}$ bin for all three pressures, but there is a 


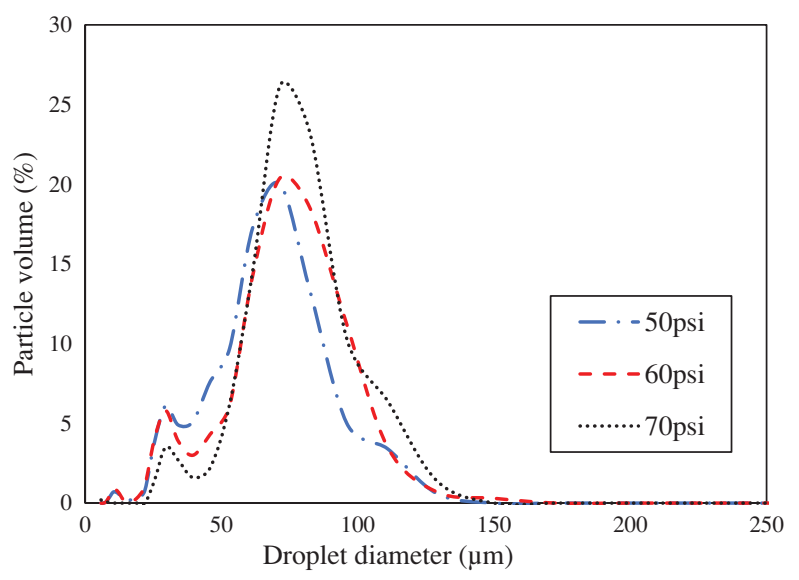

Figure 8. Injection pressure comparison of fuel RF2.

smaller peak centred around the 29.5-34.1 $\mu \mathrm{m}$ bin. This phenomenon comes becomes clearer at the highest injection pressure of 70psi, where the second peak is more consolidated and visible. This slight bi-modality can be explained by the twin fluid nature of the injector, where the fuel at the edge of the fuel sheet encounters the greatest impingement from the atomisation air and undergoes a more rapid atomisation process, resulting in smaller droplet sizes and the second peak seen in the figure. It should also be noted that all the fuels tested showed a similar droplet distribution pattern. Furthermore, it can also be seen that, as the injection pressure was increased from Figs 5 to 6 and 7, the distributions became sharper and consolidated. That is to say that the peaks become narrower and more defined, for instance with respect to Fig. 5, and Fig. 7 shows narrower, more well-defined peaks. This is in keeping with literature, where increased injection pressures result in sharper and more uniform atomisation ${ }^{(34,35)}$.

Figure 8 depicts the size distributions at the three injection pressures overlaid on each other for the fuel RF2, which is a kerosene with anticorrosion and lubricity additives, considered to be the nominal fuel in this investigation. It follows the trend that, as the injection pressure is increased, the particle distribution becomes more consolidated and the peaks narrower, indicating more uniform atomisation, which is in keeping with literature. Again, a minor peak is visible at a lower mean diameter, which can be attributed to the twin-fluid nature of the atomiser. One interesting aspect of Fig. 8 is the fact that the 70psi peak is much stronger than that of the other two injection pressures, indicating a step change in the atomisation mechanism. It might be postulated that, as the pressure approaches $70 \mathrm{psi}$, the atomisation advances to become what is known as 'prompt' atomisation ${ }^{(36)}$, where the fuel has an appreciably higher velocity and is being shot into what is effectively a stagnant flow field, thus having limited opportunity to form the ligaments, strands and wave structures mentioned in literature. Instead, the fuel is immediately disrupted into fragments without the process of primary and secondary atomisation occurring (classical atomisation). However, Lefebvre et al. ${ }^{(12)}$ goes on to state that prompt atomisation, if occurring, would result in drop diameters that are independent of characteristics of the liquid such as viscosity. This was found not to be the case further on, as the viscosity plots show a weak trend. It should also be noted that the method of atomisation is highly dependent on the operating conditions of the atomiser, and it is also possible that, inside a combustor, this atomiser would not behave the same as it would inside our spray cubicle, which has an almost stationary airflow except for the presumably 


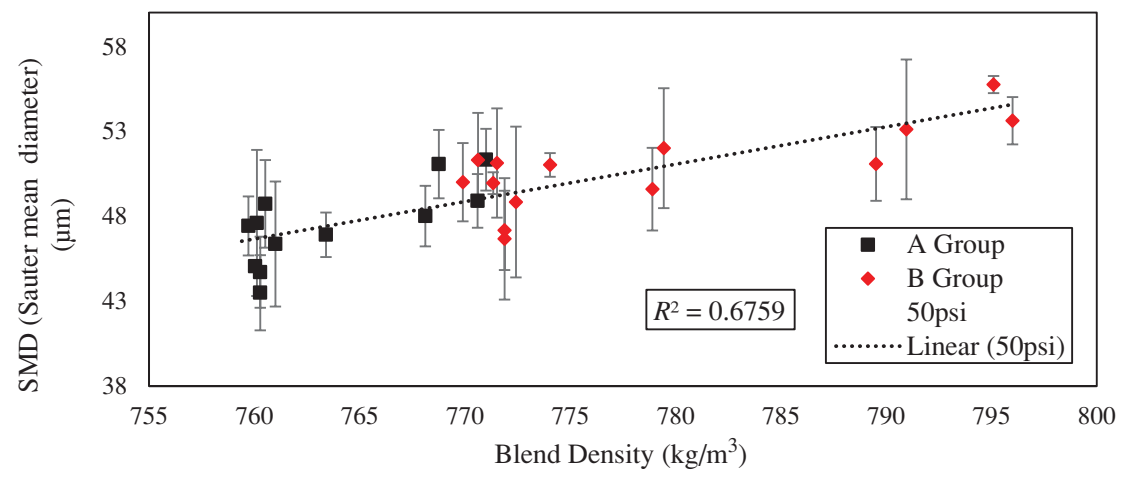

Figure 9. SMD plots for fuel groups A and B against the blend density at 50psi injection pressure.

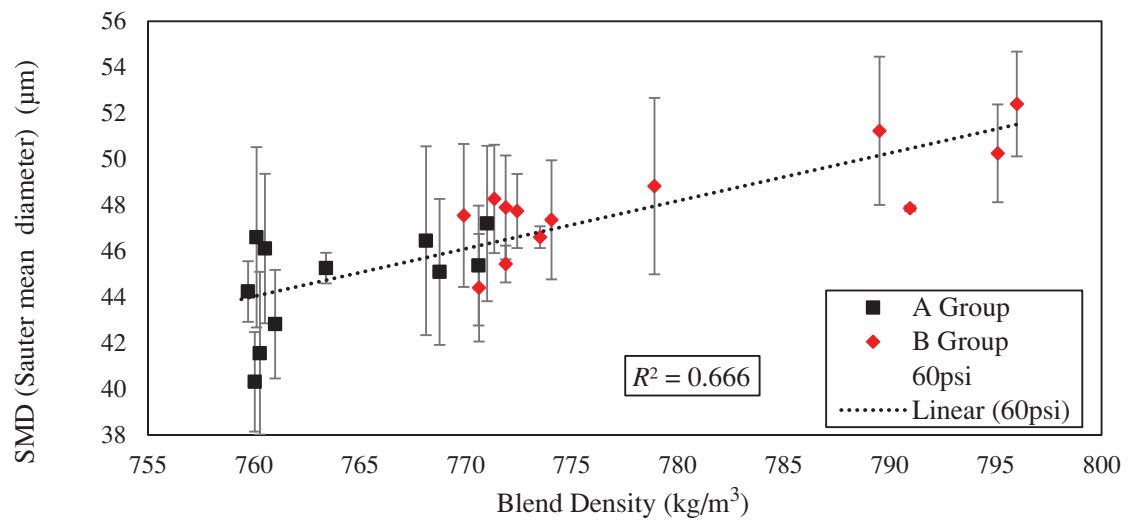

Figure 10. SMD plots for fuel groups A and B against the blend density at 60psi injection pressure.

slight suction created by the extraction system. Whilst this may not be an absolute accurate depiction of the spray behaviour inside a combustor, it would be plausible to consider this setup to be meaningful when comparing the behaviour of different fuels.

Figures 9, 10 and 11 show the SMD against the blend density for the aromatic blends in both A group and B group for the three injection pressures. Firstly, note that, as expected, the A group showed a lower SMD overall with respect to the B group. This is due to the A group being blended with only $8 \%$ by volume of aromatics, as opposed to $18 \%$ for B group. This holds true for all the injection pressures. Secondly, all three plots show a positive correlation with respect to blend density, with an $R^{2}$ value of at least 0.5 . This is in keeping with literature, where the increased density would impede the atomisation process. However, note that ASTM D1655 allows for a total fuel density range of $775-840 \mathrm{~kg} / \mathrm{m}^{3(30)}$. The majority of the A group have densities around $760 \mathrm{~kg} / \mathrm{m}^{3}$, while the B group cluster around $770 \mathrm{~kg} / \mathrm{m}^{3}$. The worst performers were indene (A5 and B5) and methylnaphthalene (A14 and B14), respectively. Both of these aromatics are polycyclic, meaning that they have more than one carbon ring with at least several double bonds between them, as well as the highest density compound densities of all the aromatics tested. Therefore, it is to be expected that they would spray poorly. The best performers were the least dense compounds (tert-butylbenzene, ethylbenzene and cumene), all of which corresponds to a blend density of $760 \mathrm{~kg} / \mathrm{m}^{3}$, the lowest measured in the A group. 


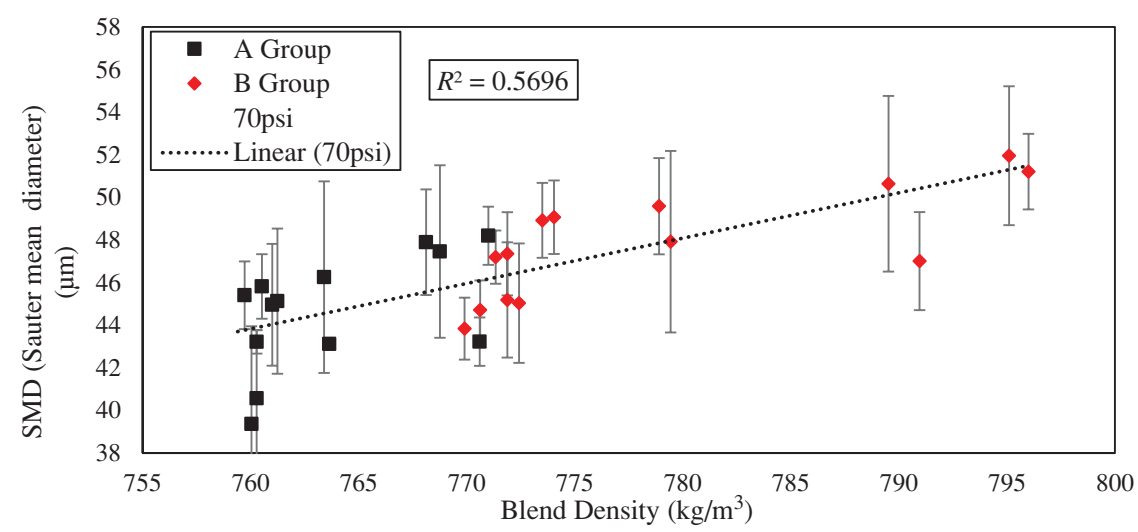

Figure 11. SMD plots for fuel groups A and B against the blend density at 70psi injection pressure.

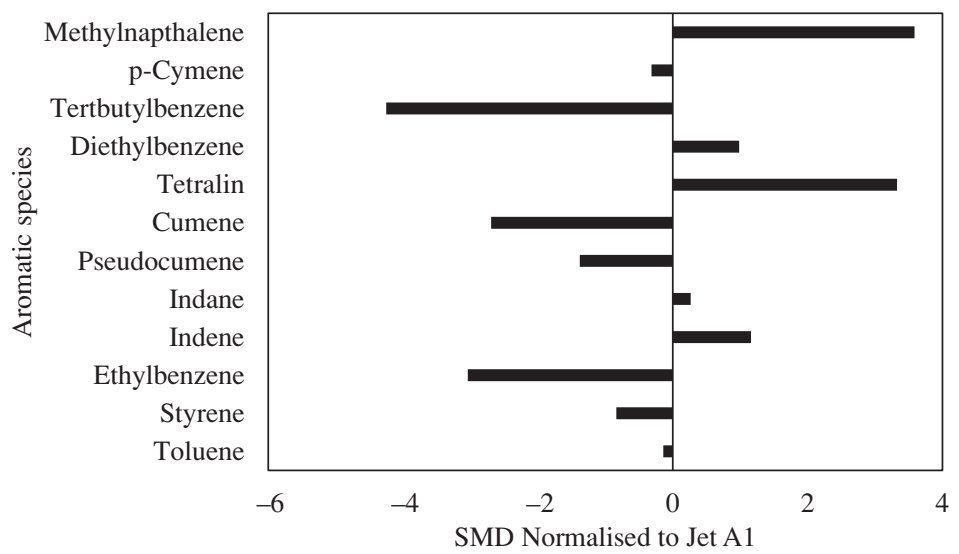

Figure 12. SMD of aromatics normalised to Jet $A(R F 1)$.

The B group showed similar results. A compound that is significant by its absence from the best performers list is toluene, the simplest possible (and therefore least dense) aromatic with the exception of pure benzene.

Toluene performed just above the best aromatic compounds at the trend line. This would indicate that it lies within the one standard deviation confidence interval. Furthermore, it is clear that the correlations are slightly dispersed, which can be attributed to the particle sizer used in this investigation; a multiple laser setup would provide a cleaner trend. Another observation is that, as the injection pressure is increased, the $R^{2}$ value drops, indicating poorer correlations, which can be attributed to the fact that the prompt atomisation threshold is being approached and some of the particles are atomised instantaneously.

Figure 12 shows the A group SMD normalised to Jet A (RF1), revealing that the blends with the simpler aromatics perform better than Jet A and the polycyclic aromatics, which perform poorly. Note that RF1 is a relatively dense Jet A $\left(803.2 \mathrm{~kg} / \mathrm{m}^{3}\right)$ with an aromatic content of $19 \%$ by mass, although the exact composition of the aromatic content remains unknown. Based on this information, it would be natural for most of the blends to outperform the nominal Jet A. Figure 13 shows a more useful comparison, with RF2, the best possible 


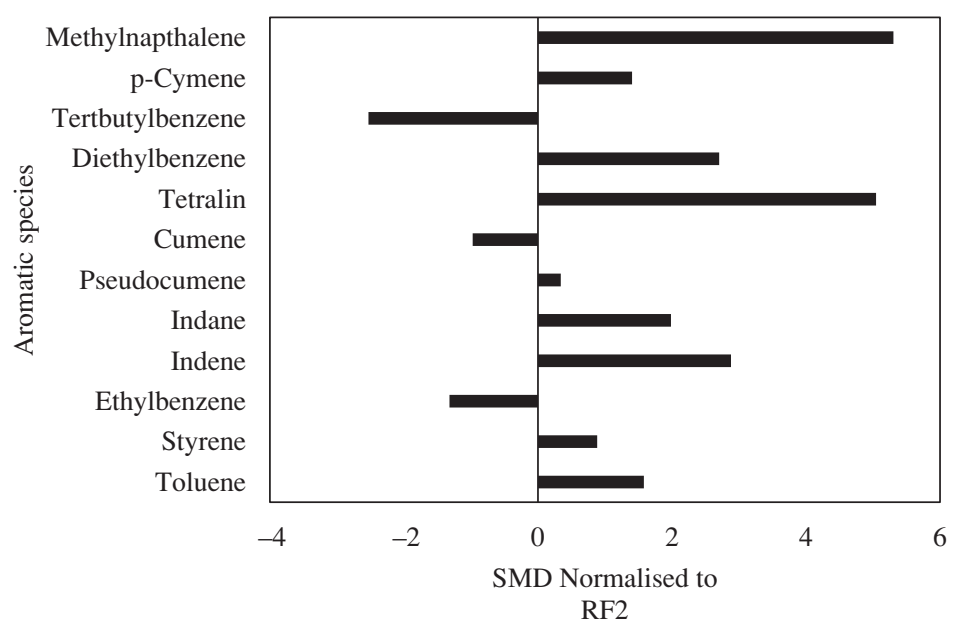

Figure 13. SMD of aromatics normalised to RF2.

jet fuel available to this investigation with an aromatic content of only $13 \%$. Here, we can see that most of the aromatic blends perform poorly with respect to RF2, which is much less dense at only $779.9 \mathrm{~kg} / \mathrm{m}^{3}$, lying just within the regulations. Here, the only compounds that manage to outperform RF2 are ethylbenzene, cumene and tert-butylbenzene. An interesting finding from the SMD versus density curves is that the aromatics that are closest chemically to pure benzene (i.e. with a benzene ring and a few methyl groups) tend to be denser than compounds with a larger aliphatic group attached, indicating that the benzene ring contributes disproportionately to the density of the compound. This is reflected by the fact that the best performers were mono-aromatic compounds with large aliphatic groups attached. This effect is further emphasised by the polyaromatic compounds, which overall performed the worst in this investigation (methylnaphthalene, indene, indan and tetralin). Even amongst these polycompounds, the worst performer was methylnaphthalene, which is the only true polyaromatic compound tested (having two full benzene rings in the molecule) while the others only have an ali-cyclic group attached to the benzene ring.

Figure 14 shows the SMD against density for some of the reference alternative fuels against their density. At $60 \mathrm{psi}$, the correlation is relatively good with an $R^{2}$ value close to 0.6 . The best-performing fuel amongst the reference fuels in terms of SMD was RF4, which is a $100 \%$ ATJ fuel with less than $1 \%$ aromatic content. As expected, the worst-performing fuel was RF3, which is the worst-case kerosene fuel with a very high flash point and an aromatic content exceeding $20 \%$.

Furthermore, it should be noted that, compared with the aromatic blends, the reference fuels show poor correlations overall. It is theorised that this is due to three possible reasons: firstly, that the density range of the fuels is narrower compared with the aromatic blends, which means that even minor deviations in the SMD have a greater impact on the $R^{2}$ value; secondly, and more likely, the fact that the compositions of the reference fuels are more complex and components other than aromatics may impact their spray characteristics; and finally, that the density is not the only variable of a liquid that will affect its spray characteristics, and with a multitude of chemical compounds, it is possible that, for example, a compound with relatively low density but high viscosity and surface tension would degrade the spray characteristics of a given reference fuel. The following results shed some light on this matter. 


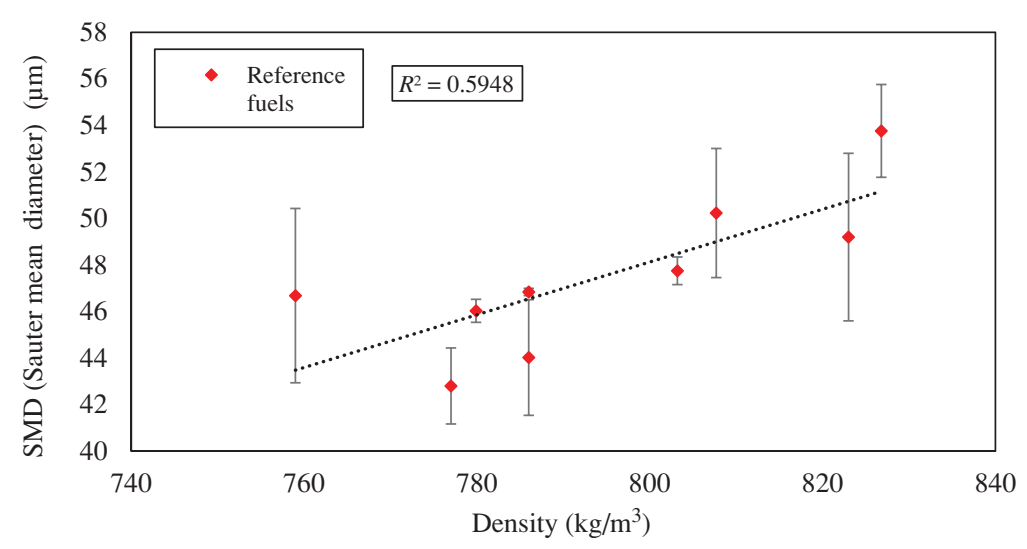

Figure 14. SMD plots for reference fuels against their density at 60 psi injection pressure.

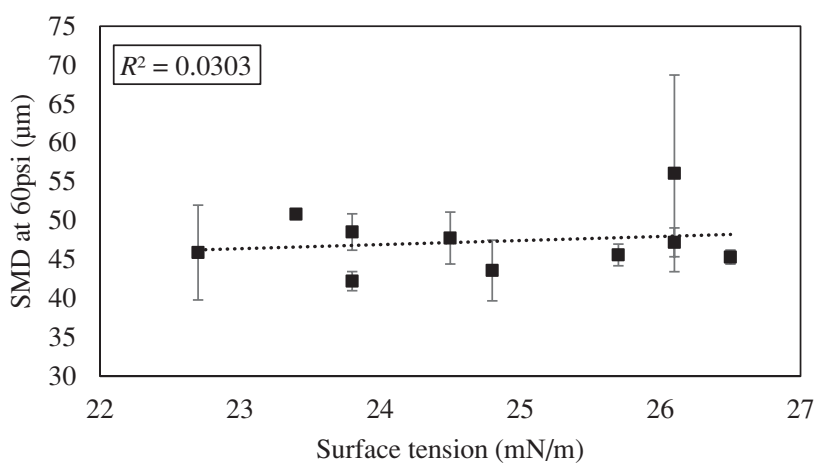

Figure 15. Reference fuel SMD against surface tension at 60psi.

\subsection{COMPARISON AGAINST FUEL PROPERTIES}

This section aims to explore how various other available fuel properties have an impact on their spray characteristics. This section only pertains to the reference fuels as the standard tests required to obtain such data are cost prohibitive and thus have not been carried out on the aromatic blends. Figure 15 depicts the SMD for the reference fuels against their surface tension measured in $\mathrm{mN} / \mathrm{m}$. As can be seen, there is a very weak correlation with an $R^{2}$ value that is positive. This is in keeping with literature, as surface tension is one of the key variables determining the spray characteristics and droplet formation, as explained in the literature review above. The lower correlation coefficients can be explained by the fact that the entire range of viscosities covers less than $5 \mathrm{mN} / \mathrm{m}$.

Figure 16 shows the relationship between the viscosity in centistokes $\left(\mathrm{mm}^{2} / \mathrm{s}\right)$ and the SMD of the reference alternative fuels. Here, we again see a slight positive correlation with increasing viscosity. Again, the viscosity range for these fuels is very narrow at only 1.4 centistokes, even less than the range for surface tension. The correlation is again keeping in line with literature, as the ease with which a liquid can flow is crucial to how it will behave under atomisation conditions ${ }^{(34,37)}$. 


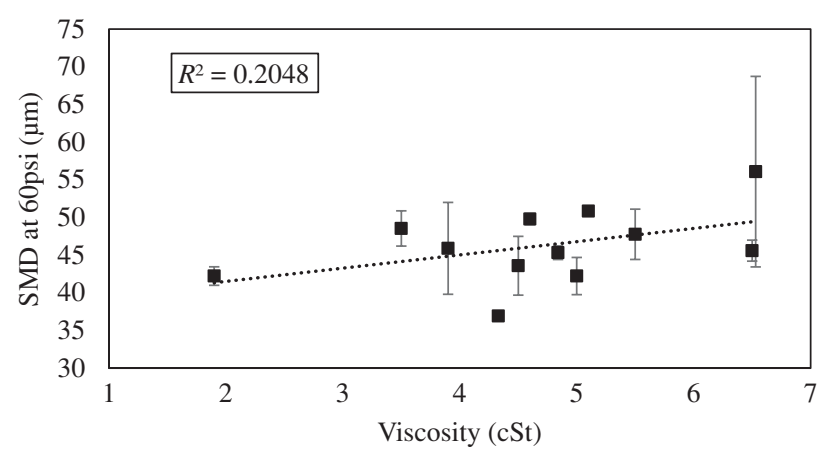

Figure 16. Reference fuel SMD against viscosity at $60 \mathrm{psi}$.

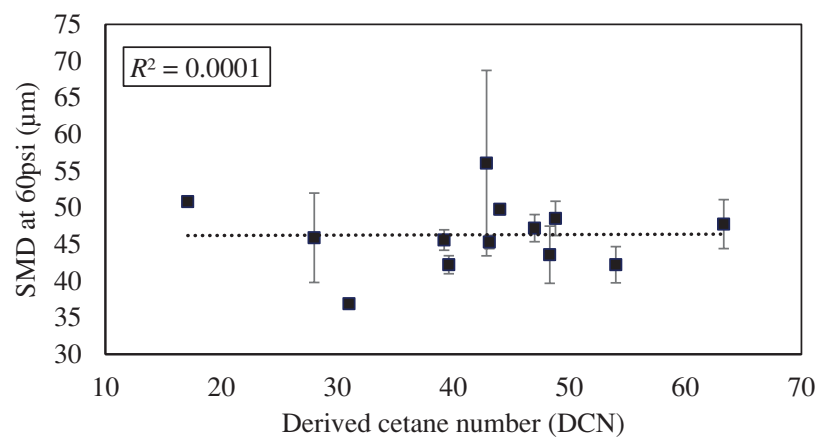

Figure 17. Reference fuel SMD against derived cetane number (DCN) at 60psi.

Figure 17 shows the relationship between SMD and DCN. This shows effectively no correlation, implying that the cetane number of a fuel is independent of its spray characteristics. This is to be expected as the spray characteristics of a given fuel are strongly dependent on its bulk fluid properties while the cetane number is more dependent on the bond and activation energies of the individual compounds of the fuel. This means that the cetane number is impacted disproportionately by certain compounds such as di-tert-butyl peroxide, which increases a fuel's cetane number, and compounds such as pentamethyl heptane, which reduces it. Jet fuels in general have high cetane numbers, which is useful for achieving good combustion characteristics. Whilst the cetane number of the aromatic blends was not tested, the solvent used to achieve the blends must have an extremely high cetane number, as it contains at least $22 \%$ by volume pure cetane, which has a cetane number of 100 . The motivation for investigating DCN stems from recent research showing that DCN is a variable of concern, especially regarding fuel LBO performance and ignition delay, which in turn impact the emissions generated by a fuel ${ }^{(38,39)}$.

Figure 18 depicts the SMD of the reference fuels against their flash point, again revealing no correlation. It can thus be concluded that the fuel's spray characteristics are independent of its flash point. Again, this is to be expected as the flash point of a fuel is related to its volatility and vapour pressure and thereby its chemical composition but not the properties of the fuel as a whole.

Two sources from literature were selected to validate this study. Firstly, the study conducted by Vouros et al. ${ }^{(5)}$, who measured the SMD of several fuel blends considering the 


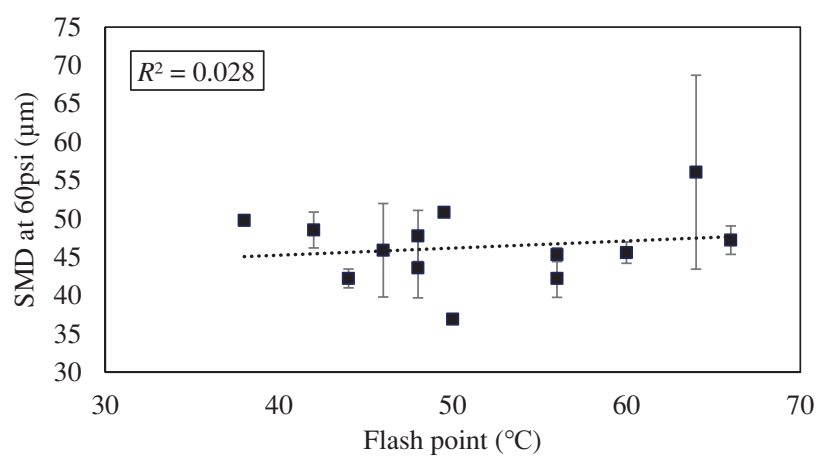

Figure 18. Reference fuel SMD against flash point at 60psi.

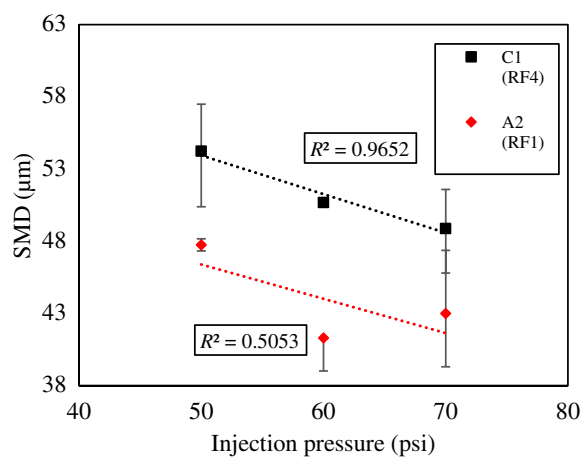

Figure 19. Injection pressure comparison for two reference fuels from Buschhagen et al. ${ }^{(6)}$.

total aromatic paraffin content for different radii of the spray and varying distances from the discharge nozzle. They also verified the trends we have seen with respect to density, viscosity and surface tension. Furthermore, the absolute values of SMD for all their fuels lay within the $40-50 \mu \mathrm{m}$ range, like those measured in this study, lending credence to the accuracy of our measurements. Secondly, some of the same reference alternative fuels were tested by Buschhagen et al., using similar injection pressures and atomiser to herein, although the measurement position was quite different, as was the spray angle generated by their injector. However, they produced graphs of SMD versus injection pressure, as shown in Fig. 19. The curve obtained from the data of the current investigation is depicted in Fig. 20. As seen from these figures, the trends are similar, but the absolute SMD values are much higher for the reference curve. This can be explained by the fact that their measurements were taken much closer to the discharging orifice with respect to this investigation. This means that the droplets analysed by Buschhagen et al. were probably still in the primary atomisation zone, in contrast to this investigation. However, note that these two sources provide a good validation for this study; the aim of which is to identify which aromatic compounds affect the spray characteristics the least.

Figures 21 and 22 show the experimental results against those calculated using a modified version of the Nukiyama-Tanasawa equation for experimental characterisation of SMD for twin-fluid atomisers ${ }^{(11)}$. 


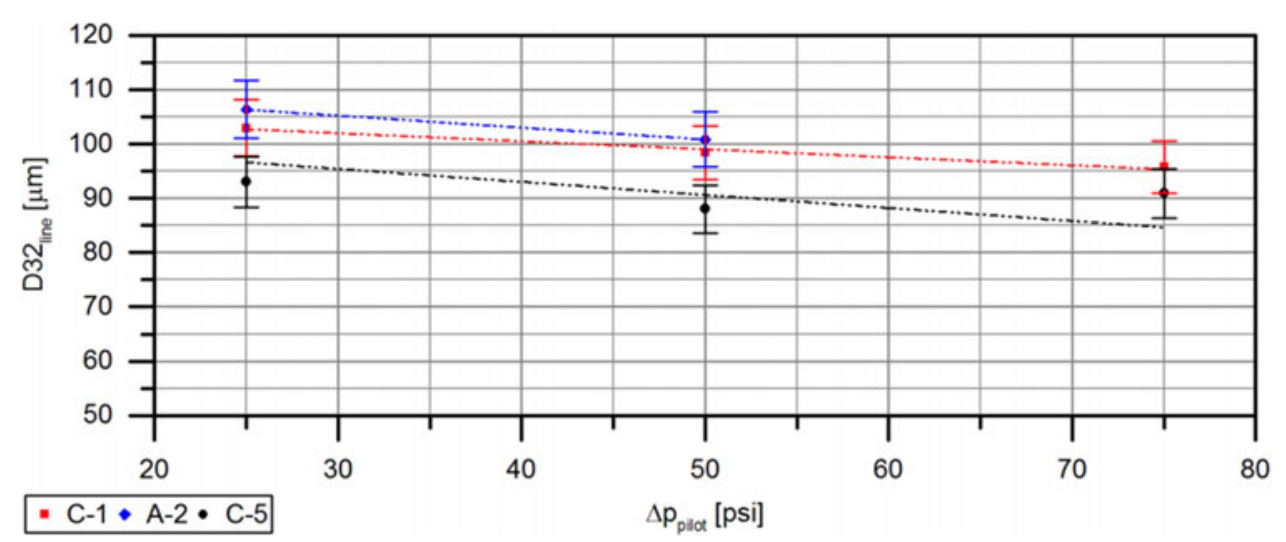

Figure 20. Injection pressure comparison of fuel RF1 (A2) and RF4 (C1).

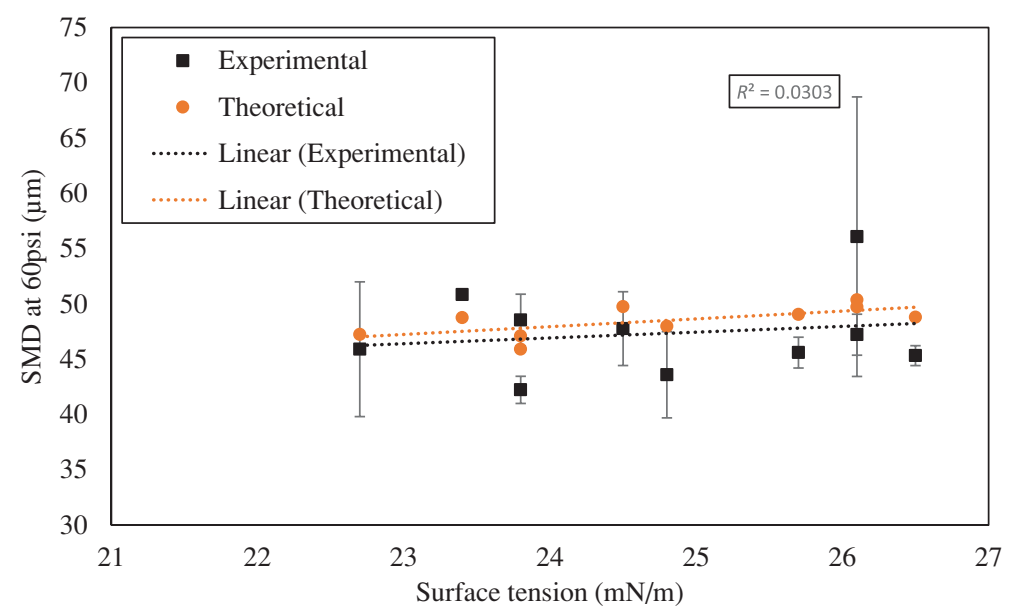

Figure 21. Theoretical versus experimental SMD against surface tension.

Note that the primary purpose of this equation is to derive the characteristics of a given injector rather than to observe the impact of various fuels on a single injector, which is why the ALR and other constant (in this investigation) features are more prominent in the equation as opposed to the fluid properties of the fuel. The original equation can be modified by using the air-to-liquid ratio instead of the individual volume flow rates, as the latter data are not available. Moreover, as the differential velocity between the liquid and stationary air was back-calculated from the SMD value for Jet A, the differential velocity could not be measured in this investigation. The modified equation is thus

$$
D_{32}=0.585\left(\sigma / \rho_{L} U_{R}^{2}\right)^{0.5}+53\left(U_{L}^{2}\right)^{0.225}(A L R)^{1.5}
$$

As seen from the figures, the viscosity and surface tension of the fuels correlate well with their theoretical values. Moreover, it can be seen that, for both the surface tension and viscosity, the theoretical and experimental results tend to approach each other with increasing SMD and 


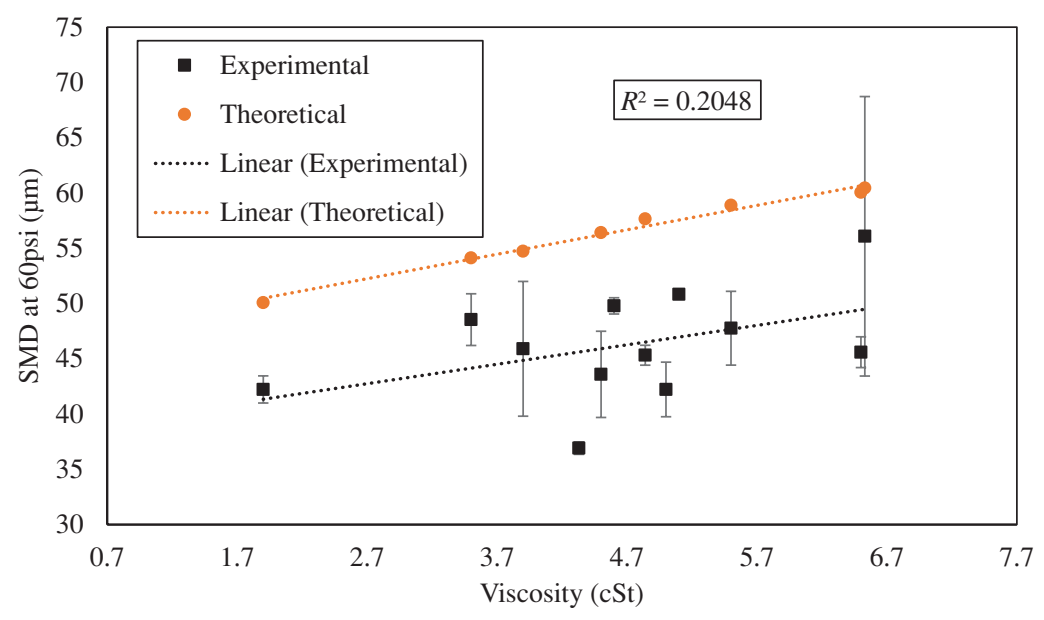

Figure 22. Theoretical versus experimental SMD against viscosity.

base variable, indicating that the experimental accuracy increases with increasing SMD. This is expected because, the larger the size of the particles, the more easily they can be detected by Malvern device. It is clear that the trends in both the experimental and theoretical values are slight. This finding can be attributed to the fact that, overall, all the fuels tested had very similar properties, with less than $17 \%$ variation in surface tension and $40 \%$ in viscosity. This is appropriate, as there would be little utility in testing fuels with wide property variations as these would obviously be poor-quality fuels.

Finally, note that this investigation tested several surrogates of aromatic blends and found that the density, surface tension and viscosity play a key role in their spray characteristics, in keeping with literature ${ }^{(5,6,25)}$. Furthermore, it was found that the benzene ring in particular contributes disproportionately to the molecular density. This is reflected in the experimental results by the fact that the best-performing aromatics were those with a large aliphatic group attached to the benzene ring. In keeping with this hypothesis, it can be concluded that the worst performers were the molecules with two benzene rings (i.e. polyaromatic hydrocarbons). This is indeed reflected in the experimental results. It would be prudent in the future to test aromatic compounds with even larger aliphatic groups attached, as this would presumably identify compounds with better spray characteristics. However it remains to be seen whether this type of compound can still effectively contribute to the lubricity and seal swell capability expected of jet fuels.

\subsection{CONCLUSIONS}

The best- and worst-performing aromatics were identified with a view to determining which aromatic can be added to jet fuel whilst impacting the spray characteristics the least and yet maintaining the crucial effect on lubricity and seal capability. The best-performing aromatics were ethylbenzene, tert-butylbenzene and cumene. These aromatics have a branched aliphatic compound attached, which should affect the density, which would explain their better spray characteristics. Another way to describe this finding is to say that compounds with the least aromaticity perform better in terms of injection. Future work could investigate the impact of 
cyclo-paraffins on spray characteristics, as the impact of RF8 on the SMD results lay outside the confidence intervals.

Another conclusion that can be drawn is that the benzene ring contributes disproportionately to the density of the aromatic molecules, indicating that an aromatic with a large aliphatic group attached could be sprayed better than a pure aromatic or polyaromatic compound. This is reflected by the fact that all three top-performing compounds (ethylbenzene, tert-butylbenzene and cumene) have aliphatic compounds attached to the benzene ring.

The SMD results compare well with those in literature, showing similar trends in all cases, which lends credence to the findings of this experiment into the spray quality of specific aromatic compounds. The observed trends would be far stronger if pure aromatics were tested. However, this was found not to be practical and was cost prohibitive. Moreover, this would not have been representative of operating conditions, as aviation fuels do not comprise purely aromatics, although aromatics do contribute to the bulk of the particulate emissions produced during their combustion.

The results of this study show how different aromatic structures, bonds and other micro properties of aromatics species impact spray and atomisation characteristics. One of the main aims of this study is to investigate how these alternative and aromatic fuels perform in the fuel injection phase of combustion.

It can be concluded that the new knowledge contributed by this work stems from the direct comparison of 16 aromatic species at two different blend ratios, in terms of the sprayed drop size. This has implications for how well these individual aromatic species behave in terms of combustion quality, thus directly impacting on the emissions generated. This leads to some clarity regarding which aromatics can be added to an alternative fuel while having the least impact on particulate emissions.

\section{REFERENCES}

1. Alajmi, A.E.S.E.T., Adam, N.M., Hairuddin, A.A. and Abdullah, L.C. Fuel atomization in gas turbines: A review of novel technology, Int J Energy Res, 2018, 43, pp 3166-3181. doi: 10.1002/er.4415.

2. Lefebvre, A.H. Properties of sprays, Part Part Syst Charact, 1989, 6, 176-186. doi: $10.1002 /$ ppsc. 19890060129.

3. Lieuwen, T.C. Unsteady Combustor, Physics, Cambridge University Press, 2012.

4. Lieuwen, T.C. and YANG, V. Combustion Instabilities In Gas Turbine Engines, American Institute of Aeronautics and Astronautics, 2006, Reston, VA. doi: 10.2514/4.866807.

5. Vouros, A., Vouros, A. and Panidis, T. Spray characteristics of alternative aviation fuel blends, Aerospace, 2017, 4, 18. doi: 10.3390/aerospace4020018.

6. Buschhagen, T., Zhang, R.Z., Bokhart, A.J., GejJ, R.M., Naik, S.V., Lucht, R.P., Gore, J.P., SoJka, P.E., Slabaugh, C.D. and Meyer, S. Effect of aviation fuel type and fuel injection conditions on non-reacting spray characteristics of a hybrid airblast fuel injector, 54th AIAA Aerosp Sci Meet, American Institute of Aeronautics and Astronautics, Reston, Virginia, 2016, pp 1-18. doi: 10.2514/6.2016-1154.

7. Heyne, J.S., Peiffer, E., Colket, M.B., Jardines, A., Shaw, C., Moder, J.P., Roquemore, W.M., Edwards, J.T., Li, C., Rumizen, M. and Gupta, M. Year 3 of the national jet fuels combustion program: practical and scientific impacts of alternative jet fuel research, 2018 AIAA Aerosp Sci Meet, American Institute of Aeronautics and Astronautics, Reston, Virginia, 2018. doi: $10.2514 / 6.2018-1667$.

8. ZhaO, J., ZhaO, B., WANG, X. and YAng, X. Atomization performance and TG analysis of Fischer-Tropsch fuel compared with RP-3 aviation fuel, Int J Hydrogen Energy, 2017, 42, pp 18626-18632. doi: 10.1016/j.ijhydene.2017.04.137. 
9. KAnNaIYAN, K. and SADR, R. Experimental investigation of spray characteristics of alternative aviation fuels, Energy Convers Manag, 2014, 88, pp 1060-1069. doi: 10.1016/j.enconman.2014.09.037.

10. Mansour, A. and Chigier, N. Dynamic behavior of liquid sheets, Phys Fluids A Fluid Dyn, 1991, 3, pp 2971-2980. doi: 10.1063/1.857839.

11. Nukiyama, S. and Tanasawa, Y. An experiment on the atomization of liquid by means of an air stream (the 2nd Report), Trans Japan Soc Mech Eng, 1938, 4, pp 138-143. doi: 10.1299/kikai1938.4.15_138.

12. Lefebvre, A.H. and Ballal, D.R. Gas Turbine Combustion; Alternative Fuels and Emissions. CRC Press, 2010. doi: 10.1201/9781420086058.

13. DeWitt, M.J., Corporan, E., Graham, J. and Minus, D. Effects of aromatic type and concentration in fischer-tropsch fuel on emissions production and material compatibility, Energy \& Fuels, 2008, 22, pp 2411-2418. doi: 10.1021/ef8001179.

14. Khandelwal, B., Wijesinghe, C.J. and Sriraman, S. Effect of alternative fuels on emissions and engine compatibility, A.K. Runchal, A.K. Gupta, A. Kushari, A. De and S.K. Aggarwal (Eds.) Energy Propuls A Sustain Technol Approach, Springer Singapore, 2018, Singapore, pp. 27-50. doi: 10.1007/978-981-10-7473-8_2.

15. Chen, K., Liu, H. and XIA, Z. The impacts of aromatic contents in aviation jet fuel on the volume swell of the aircraft fuel tank sealants, SAE Int J Aerosp, 2013, 6, 2013-01-9001. doi: 10.4271/2013-01-9001.

16. Liu, Y. and Wilson, C.W. Investigation into the impact of n-decane, decalin, and isoparaffinic solvent on elastomeric sealing materials, Adv Mech Eng, 2012, 4, 127430. doi: $10.1155 / 2012 / 127430$.

17. Zheng, L., Cronly, J., Ubogu, E., Ahmed, I., Zhang, Y. and Khandelwal, B. Experimental investigation on alternative fuel combustion performance using a gas turbine combustor, Appl Energy, 2019, 238, pp 1530-1542. doi: 10.1016/j.apenergy.2019.01.175.

18. Khandelwal, B., Cronly, J., Ahmed, I.S., Wijesinghe, C.J. and Lewis, C. The effect of alternative fuels on gaseous and particulate matter (PM) emission performance in an auxiliary power unit (APU), Aeronaut J, 2019, 123, pp 617-634. doi: 10.1017/aer.2019.16.

19. Blakey, S., Rye, L. and Wilson, C.W. Aviation gas turbine alternative fuels: A review, Proc Combust Inst, 2011, 33, pp 2863-2885. doi: 10.1016/j.proci.2010.09.011.

20. Liu, C., Liu, F., YANG, J., Mu, Y. and Xu, G. Investigations of the effects of spray characteristics on the flame pattern and combustion stability of a swirl-cup combustor, Fuel, 139, 2015, pp 529-536. doi: 10.1016/j.fuel.2014.08.072.

21. Shanmugadas, K.P., Chakravarthy, S.R., Chiranthan, R.N., Sekar, J. and Krishnaswami, S. Characterization of wall filming and atomization inside a gas-turbine swirl injector, Exp Fluids, 2018, 59, p 151. doi: 10.1007/s00348-018-2606-0.

22. Sivakumar, D., Vankeswaram, S.K., Sakthikumar, R. and Raghunandan, B.N. Analysis on the atomization characteristics of aviation biofuel discharging from simplex swirl atomizer, Int $J$ Multiph Flow, 2015, 72, pp 88-96. doi: 10.1016/j.ijmultiphaseflow.2015.02.009.

23. Sallevelt, J.L.H.P., Gudde, J.E.P., Pozarlik, A.K. and Brem, G. The impact of spray quality on the combustion of a viscous biofuel in a micro gas turbine, Appl Energy, 2014, 132, pp 575-585. doi: 10.1016/j.apenergy.2014.07.030.

24. Crayford, A.P., Lacan, F., Runyon, J., Bowen, P.J., Balwadkar, S., Harper, J. and Pugh, D.G. Manufacture, characterization and stability limits of an AM prefilming air-blast atomizer, Proc. ASME Turbo Expo, 2019. doi: 10.1115/GT2019-91624.

25. Delacruzgarcia, M., Mastorakos, E. and Dowling, A. Investigations on the self-excited oscillations in a kerosene spray flame, Combust Flame, 2009, 156, pp 374-384. doi: 10.1016/j.combustflame.2008.11.018.

26. Penner, S. and Williams, F. Recent studies on flame stabilization of premixed turbulent gases, Appl Mech Rev, 1957, 10, pp 229-237.

27. Colket, M., Edwards, T., Dryer, F., Williams, S., Cernansky, N., Miller, D., Egolfopoulos, F., DRYER, F. and BELLAN, J. Identification of target validation data for development of surrogate jet fuels, 46th AIAA Aerosp Sci Meet Exhib, American Institute of Aeronautics and Astronautics, Reston, Virigina, 2008. doi: 10.2514/6.2008-972.

28. Friedman, R. Recent Trends in Aviation Turbine Fuel Properties, Cleveland, OH, 1982. https://ntrs.nasa.gov/search.jsp?R=19830003070 (accessed March 2, 2020). 
29. Schripp, T., Anderson, B., Crosbie, E.C., Moore, R.H., Herrmann, F., Owald, P., Wahl, C., Kapernaum, M., Khler, M., Le Clerce, P., Rauch, B., Eichler, P., Mikoviny, T. and Wisthaler, A. Impact of alternative jet fuels on engine exhaust composition during the 2015 ECLIF ground-based measurements campaign, Environ Sci Technol, 2018, 52, pp 4969-4978. doi: 10.1021/acs.est.7b06244.

30. ASTM, ASTM D1655 18a Standard Specification for Aviation Turbine Fuels, 2018. doi: 10.1520/D1655-19A.

31. Ministry of Defence UK Aviation fuels committee, Defence Standard 91-091, United Kingdom, 2016. https://global.ihs.com/doc_detail.cfm?document_name=DEFSTAN91-091\&item_s_key= 00450750

32. Barreras, F., Lozano, A., Barroso, J. and Lincheta, E. Experimental characterization of industrial twin-fluid atomizers, At Sprays, 2006, 16, pp 127-146. doi: 10.1615/AtomizSpr.v16.i2.10.

33. Chin, J.S., LI, W.M. and Zhang, Y. Experimental study of the effect of dense spray on drop size measurement by light scattering technology, J Eng Gas Turbines Power, 1992, 114, pp 82-88. doi: 10.1115/1.2906310.

34. Charalampous, G. and Hardalupas, Y. How do liquid fuel physical properties affect liquid jet development in atomisers? Phys Fluids, 2016, 28, p 102106. doi: 10.1063/1.4965447.

35. Carvalho, I.S. and Heitor, M.V. Liquid film break-up in a model of a prefilming airblast nozzle, Exp Fluids, 1998, 24, pp 408-415. doi: 10.1007/s003480050190.

36. LeFEBVRE, A.H. Energy considerations in twin-fluid atomization, J Eng Gas Turbines Power, 1992, 114, pp 89-96. doi: 10.1115/1.2906311.

37. Tolman, R.C. The effect of droplet size on surface tension, J Chem Phys, 1949, 17, pp 333-337. doi: 10.1063/1.1747247.

38. Stachler, R.D., Heyne, J.S., Stouffer, S.D., Miller, J.D. and Roquemore, W.M. Investigation of combustion emissions from conventional and alternative aviation fuels in a well-stirred reactor, AIAA SciTech Forum - 55th AIAA Aerosp. Sci. Meet., American Institute of Aeronautics and Astronautics, 2017. doi: 10.2514/6.2017-0382.

39. SAlvi, A.A., Assanis, D. and FILIPI, Z. Impact of physical and chemical properties of alternative fuels on combustion, gaseous emissions, and particulate matter during steady and transient engine operation, Energy and Fuels, ACS, 2012, pp 4231-4241. doi: 10.1021/ef300531r. 